\title{
Is repositioning effective for pressure injury prevention in adults? A Cochrane Review summary with commentary
}

\author{
Derya Soy Buğdaycı $(1)$, Nurdan Paker(1) \\ Department of Physical Therapy and Rehabilitation, University of Health Sciences, Istanbul Physical Therapy Rehabilitation Training and Research Hospital, Istanbul, Turkey
}

Received: November 26, 2021 Accepted: November 30, 2021 Published online: December 01, 2021

The aim of this commentary is to discuss in a rehabilitation perspective relative to the Cochrane Review, “Repositioning for pressure injury prevention in adults" by Gillespie, Walker, Latimer, Thalib, Whitty, McInnes, Chaboyer ${ }^{[1]}$ published by the Cochrane Wounds Group. This Cochrane Corner is produced in agreement with the Turkish Journal of Physical Medicine and Rehabilitation by Cochrane Rehabilitation with views* of the review summary authors in the "implications for practice" section.

Background: Pressure injury (PI) is a serious problem for health care systems, affecting the health of more than 7 million people all around the world. ${ }^{[2]}$ Over 2.5 million people in the US develop PI and 60,000 of them die, similarly in the UK 700,000 people are affected with a result of 29,000 deaths. ${ }^{[3]}$ Pressure injury treatment cost is high. The cost has been calculated as US $\$ 10.708$ per patient. ${ }^{[4]}$ Pressure injury is observed in $1 / 10$ hospitalized adult patients and most of these wounds are superficial and are preventable. ${ }^{[5]}$ Unless PI is cured, it negatively affects the lives of the elderly and immobile people (e.g., pain, sepsis, QoL, death). ${ }^{[6]}$ In 2014, a pressure ulcer is defined as "a localized injury to the skin or underlying tissue usually over a bony prominence as a result of pressure or pressure in combination with shear". ${ }^{[7]}$ In 2016, instead of pressure ulcer, the term PI was accepted with a wider range of injuries such as the ones occurring under a medical or another device. ${ }^{[8]}$ For a person with normal physical, mental, and sensory status, prolonged pressure causes pain and discomfort, which leads the person to change his/her body position in order to get rid of the pressure. However, for persons who cannot change their position due to various reasons (age, plegia, sensory defect, etc.), repositioning in certain frequencies is recommended to prevent PI. In the Cochrane Review of 2014, evidence for repositioning frequency and appropriate positioning was found to be insufficient. ${ }^{[9]}$ In a clinical practice guideline published in 2019, "determining repositioning frequency with consideration to the individual's level of activity, mobility and ability to independently reposition" was strongly recommended at the B2 level of evidence, and "using the $30^{\circ}$ lateral side-lying position in preference to the $90^{\circ}$ side-lying position when positioning" was recommended at C level of evidence. ${ }^{[10]}$ This current Cochrane review is an updated review of evidence on various repositioning regimes to evaluate PI prevention in immobile people without considering the supporting mattress type.

\footnotetext{
Corresponding author: Derya Soy Buğdaycı, MD. SBÜ İstanbul Fizik Tedavi Rehabilitasyon Eğitim ve Araştırma Hastanesi, Fizik Tedavi ve Rehabilitasyon Kliniğí, 34186 Bahçelievler, İstanbul, Türkiye. e-mail: deryabugdayci@yahoo.com Reviews are regularly updated as new evidence emerges and in response to feedback, and the Cochrane Database of Systematic Reviews should be consulted for the most recent version of the review.

*The views expressed in the summary with commentary are those of the Cochrane Corner authors (different than the original Cochrane Review authors) and do not represent the Cochrane Library or Wiley.
} 
Repositioning for pressure injury prevention in adults (Gillespie et al., 2020) ${ }^{[1]}$

\section{What is the aim of this Cochrane review?}

This review aimed to compare different repositioning frequencies and positioning regimes in adults staying in long-term care settings and hospitals, to determine effective ways to prevent PI.

\section{What was studied in the Cochrane review?}

The population addressed in this review was adults without any existing PI who were admitted to healthcare facilities or long-term care settings. The interventions studied were repositioning frequencies and patient positions, regardless of the inclusion of standard clinical care strategies (e.g., type of support surfaces used). The interventions were compared to assess their effect on the incidence of PI. 2-, 3-, 4-hourly repositioning frequencies, as well as positioning relative to $30^{\circ}$ recumbent tilt and $90^{\circ}$ lateral rotation positioning. Also, repositioning regimes were compared with standard care. The primary outcomes studied were the rates of incidence of PI of any stage. And the secondary outcomes were health-related quality of life which includes author reported utility scores, pain, patient satisfaction, and costs relevant to the prevention, visits to health professionals, and avoidance of PI prevention.

\section{Search methodology and up-to-dateness of the Cochrane review?}

The review authors searched for studies that had been published up to February 12, 2019, in electronic databases including the Cochrane Wounds Specialised Register, the Cochrane Central Register of Controlled Trials, Ovid MEDLINE and Ovid Embase, EBSCO CINAHL Plus and the NHS Economic Evaluation Database.

Authors also searched clinical trials registries including the National Institutes of Health Ongoing Trials Register, the World Health Organization (WHO) International Clinical Trials Registry Platform (ICTRP) and the EU Clinical Trials Register, all up to March 10, 2019.

\section{What are the main results of the Cochrane review?}

The review included eight randomized controlled studies (RCT and cluster-RCT) involving 3,941 individuals. $^{[11-18]}$ Six studies reported the rate of participants developing PI of any stage. In two of the eight studies, cost evaluations were also reported.
The follow-up period in studies ranged from 24 hours to 28 days. All studies were at high risk of bias.

\section{Incidence of PI according to repositioning frequencies}

- In three studies involving 1,074 participants ${ }^{[11-13]}$ 2-hourly and 4 hourly repositioning frequencies were compared regardless of the support surface. The cumulative results of the three studies (pooled analysis) of the repositioning frequencies suggest the certainty of evidence is very low relative to increased or decreased incidence of PI (fixed-effect; $\mathrm{I}^{2}=45 \%$, pooled risk ratio $[R R]: 1.06,95 \%$ Confidence Interval [CI]: 0.80 to 1.41 ).

- Comparisons in these studies were not included in the pooled analysis. The comparison of 2 -hourly and 3 hourly repositioning frequencies on high-density foam mattresses in one of the trials with 3 arms involving 967 adults showed no clear difference in PI risk (RR: 4.06, 95\% CI: 0.87 to 18.98 ) based on low certainty evidence. ${ }^{[1]]}$

- A possibility of reduction in PI incidence with 3-hourly repositioning frequency was suggested in one of the arms of the same trial when compared with 4-hourly repositioning frequency based on low certainty of evidence (RR: $0.20,95 \%$ CI: 0.04 to 0.92$)^{[11]}$ and high risk of bias.

- The comparison of 2-hourly and 3-hourly repositioning frequencies on standard mattresses as well as 4-hourly and 6-hourly repositioning frequencies on viscoelastic foam mattresses revealed an RR of 0.90 (95\% CI: 0.69 to 1.16 ) and an RR of 0.73 (95\% CI: 0.53 to 1.02 ). These comparisons were based on very low certainty evidence in one study involving 262 adults thus their actual effects are unknown. ${ }^{[12]}$

\section{Incidence of PI according to positioning regimes}

\section{Pooled analysis}

- Among 4 studies comparing distinct tilt positions, 2 studies involving 252 adults were subject to a meta-analysis which revealed no clear difference when $30^{\circ}$ tilt was compared with $90^{\circ}$ tilt positioning in terms of the PI stage 1 or 2 incidence/proportion with a RR of 0.62 (95\% CI: 0.10 to 3.97 ) based on very low certainty evidence and downgraded due to serious design limitations and very serious imprecision. ${ }^{[15,16]}$ 


\section{Single studies}

- In one study (120 participants in three groups) tilts of $30^{\circ}$ and $45^{\circ}$ were compared with usual care where no PI occurred in any of the adults based on low certainty of evidence. ${ }^{[17]}$

- In one study (116 participants), prone position and usual supine position was compared with the indication of higher stage 1 PI incidence in the prone position and no clear difference regarding stage $2 \mathrm{PI}$ incidence between groups based on low certainty evidence. ${ }^{[18]}$

\section{Secondary outcomes for quality of life, pain, and satisfaction}

No studies reported the secondary outcomes mentioned above.

\section{Cost analysis}

In the two studies reporting cost analysis, the limited data indicates there is no clear evidence about whether the interventions were cost-effective when compared to standard care.

\section{What did the authors conclude about the evidence?}

The authors concluded there was insufficient evidence to draw a reliable conclusion. Thus, it is difficult to say whether a different repositioning frequency (2-hourly versus 3-hourly; 4-hourly versus 6-hourly; 2-hourly versus 4-hourly) or a different position (the $30^{\circ}$ tilt compared with the $90^{\circ}$ lateral position) is more effective than another for preventing PI. High-quality studies with adequate power are required to evaluate the effectiveness of repositioning regimens on PI prevention. For future studies, it is recommended that the number of participants should be larger, different risk groups should be included, up to date technologies and manual methods should be compared in registration, follow-up and care stages, and financial analysis thereof should be made.

\section{What are the implications of the Cochrane evidence for practice in rehabilitation?}

The presence of PI is one of the deterrent factors for particularly immobile patients to participate in a rehabilitation program. Treatment of PI takes a long time and increases immobility, thus creating a vicious circle for the patient. ${ }^{[19]}$ Therefore, preventing PI is more important than treating it. This review was able to include only the studies which assessed the effectiveness of repositioning frequencies and regimens on the incidence of PI, for mostly elderly, physically dependent, immobile, long-term cared, and hospitalized participants. Evidence was judged as low and very low certainty with the implication that the actual effects are not known. Thus, the findings obtained from this review do not provide sufficient evidence to guide rehabilitation professionals on effective methods to prevent PI because of the high level of uncertainty. Furthermore, the population in these studies were not specific to patients commonly treated by rehabilitation professionals (spinal cord injury, geriatric, and traumatic brain injury). For future studies in the prevention of PI, any study focusing on specific risk groups (i.e., spinal cord injury, traumatic brain injury, geriatric, pediatric, etc.), acute and chronic patient groups, may produce more informative results, depending on how the study is designed and executed. There is also a need for studies to evaluate the effects of PI prevention on QoL, pain and patient satisfaction, not only during the hospitalization period but also in diverse settings including the community.

\section{Acknowledgement}

The authors thank Cochrane Rehabilitation and the Cochrane Wounds Group for reviewing the contents of the Cochrane Corner.

\section{Declaration of conflicting interests}

The authors declared no conflicts of interest with respect to the authorship and/or publication of this article.

Funding

The authors received no financial support for the research and/or authorship of this article.

\section{REFERENCES}

1. Gillespie BM, Walker RM, Latimer SL, Thalib L, Whitty JA, McInnes E, et al. Repositioning for pressure injury prevention in adults. Cochrane Database Syst Rev 2020;6:CD009958. doi: 10.1002/14651858.CD009958.pub3.

2. Sen CK, Gordillo GM, Roy S, Kirsner R, Lambert L, Hunt TK, et al. Human skin wounds: A major and snowballing threat to public health and the economy. Wound Repair Regen 2009;17:763-71.

3. Padula WV, Pronovost PJ. Addressing the multisectoral impact of pressure injuries in the USA, UK and abroad. BMJ Qual Saf 2018;27:171-3.

4. Padula WV, Delarmente BA. The national cost of hospitalacquired pressure injuries in the United States. Int Wound J 2019;16:634-40.

5. Li Z, Lin F, Thalib L, Chaboyer W. Global prevalence and incidence of pressure injuries in hospitalised adult patients: A systematic review and meta-analysis. Int J Nurs Stud 2020;105:103546.

6. Jaul E, Calderon-Margalit R. Systemic factors and mortality in elderly patients with pressure ulcers. Int Wound J 2015;12:254-9. 
7. National Pressure Ulcer Advisory Panel, European Pressure Ulcer Advisory Panel and Pan Pacific Pressure Injury Alliance. Prevention and Treatment of Pressure Ulcers: Quick Reference Guide. In: Haesler E, editor. Cambridge Media: Osborne Park Australia; 2014.

8. Edsberg LE, Black JM, Goldberg M, McNichol L, Moore L, Sieggreen M. Revised National Pressure Ulcer Advisory Panel pressure injury staging system: Revised pressure injury staging system. J Wound Ostomy Continence Nurs 2016;43:585-97.

9. Gillespie BM, Chaboyer WP, McInnes E, Kent B, Whitty JA, Thalib L. Repositioning for pressure ulcer prevention in adults. Cochrane Database Syst Rev 2014;2014:CD009958.

10. European Pressure Ulcer Advisory Panel, National Pressure Injury Advisory Panel and Pan Pacific Pressure Injury Alliance. Prevention and treatment of pressure ulcers/ injuries: clinical practice guideline. 3rd ed. 2019. Available at www.internationalguideline.com.

11. Bergstrom N, Horn SD, Rapp MP, Stern A, Barrett R, Watkiss M. Turning for Ulcer Reduction: A multisite randomized clinical trial in nursing homes. J Am Geriatr Soc 2013;61:1705-13.

12. Defloor T, De Bacquer D, Grypdonck MH. The effect of various combinations of turning and pressure reducing devices on the incidence of pressure ulcers. Int J Nurs Stud 2005;42:37-46.

13. Manzano F, Colmenero $M$, Pérez-Pérez AM, Roldán D, Jiménez-Quintana Mdel M, Mañas MR, et al. Comparison of two repositioning schedules for the prevention of pressure ulcers in patients on mechanical ventilation with alternating pressure air mattresses. Intensive Care Med 2014;40:1679-87.

14. Pickham D, Berte N, Pihulic M, Valdez A, Mayer B, Desai M. Effect of a wearable patient sensor on care delivery for preventing pressure injuries in acutely ill adults: A pragmatic randomized clinical trial (LS-HAPI study). Int J Nurs Stud 2018;80:12-9.

15. Moore Z, Cowman S, Conroy RM. A randomised controlled clinical trial of repositioning, using the $30^{\circ}$ tilt, for the prevention of pressure ulcers. J Clin Nurs 2011;20:2633-44.

16. Young T. The 30 degree tilt position vs the 90 degree lateral and supine positions in reducing the incidence of non-blanching erythema in a hospital inpatient population: A randomised controlled trial. J Tissue Viability 2004;14:88, 90, 92-6.

17. Ghezeljeh T, Kalhor L, Moghadam O, Lahiji M, Haghani H. The comparison of the effect of the head of bed elevation to 30 and 45 degrees on the incidence of ventilator associated pneumonia and the risk for pressure ulcers: a controlled randomised clinical trial. Iranian Red Cresecent Medical Journal 2017;19:e14224.

18. Zhou X, Liu D, Long Y, Zhang Q, Cui N, He H, et al. The effects of prone position ventilation combined with recruitment maneuvers on outcomes in patients with severe acute respiratory distress syndrome. Zhonghua Nei Ke Za Zhi 2014;53:437-41.

19. Gedde MH, Lilleberg HS, Aßmus J, Gilhus NE, Rekand T. Traumatic vs non-traumatic spinal cord injury: A comparison of primary rehabilitation outcomes and complications during hospitalization. J Spinal Cord Med 2019;42:695-701. 